\title{
Influence of Calcination on Different Properties of Sugarcane Bagasse and Waste Ash
}

\author{
M. S. Sultana*, M. A. Rahman, M. N. Zaman, A. N. Ahmed \\ Institute of Mining, Mineralogy and Metallurgy, BCSIR, Science Laboratory Road, Khonjonpur, \\ Joypurhat-5900, Bangladesh
}

Received 28 May 2015, accepted in final revised form 11 June 2015

\begin{abstract}
Sugarcane bagasse is a fibrous waste product and important biomass sources, which is used as a fuel in the sugar industry. Bagasse ash is an industrial waste that mainly consists of high amount of silica and carbon materials. In this study sugarcane bagasse ash (SCBA) and sugarcane waste ash (SCWA) were calcined at $400^{\circ} \mathrm{C}, 600^{\circ} \mathrm{C}, 800^{\circ} \mathrm{C}$ and $1000^{\circ} \mathrm{C}$ for $2 \mathrm{~h}$. These samples were characterized in order to evaluate the possibility of their use in different industries. XRF and XRD analyses were done for chemical and phase analysis of both calcined samples. The chemical composition of calcined SCBA and SCWA indicated that samples had similar compositions of other pozzolanic material. Carbon content has been determined by elemental analyzer. With increasing temperature the percentage of carbon content decreases in both cases. As temperature increases, the color of SCBA and SCWA samples changing from black to grey and white, which also indicates that the carbon content present in the SCBA were reasonably reduced. XRD patterns showed that crystallinity increases with influence of calcining temperature for both ash samples.
\end{abstract}

Keywords: Bagasse ash; Waste ash; Carbon content; Calcination.

(c) 2015 JSR Publications. ISSN: 2070-0237 (Print); 2070-0245 (Online). All rights reserved.

doi: http://dx.doi.org/10.3329/jsr.v7i3.23523

J. Sci. Res. 7 (3), 151-157 (2015)

\section{Introduction}

Sugarcane bagasse (SCB) is a voluminous byproduct from the sugar mills when juices are extracted from the canes. However, generally it is used as fuel to fire furnaces in the same sugar mills that yields about $8-10 \%$ ashes containing high amounts of unburnt matter, silicon, aluminum, iron and calcium oxides. But the ashes obtained directly from the mills are not reactive because those are burnt under uncontrolled conditions and at very high temperature. Ganesan et al. [1] stated that 1 ton of sugarcane generates $280 \mathrm{~kg}$ of bagasse and that based on economics as well as environmental related issues enormous efforts

* Corresponding author: shammiswe@yahoo.com 
have been directed worldwide towards bagasse management issues i.e. utilization, storage and disposal.

The ash, therefore, becomes an industrial waste and poses disposal problems. It's utilization as an adsorbent as well as mineral admixture in cement and concrete has been examined [2]. Ganesan et al. [1] reported the use of sugarcane bagasse ash (SCBA) waste as supplementary cementing materials. It is stated that the SCBA waste is an effective mineral admixture with $20 \%$ as optimal replacement ratio of cement. Usually SCBA may contain black particles due to the presence of carbon (Fig. 1). According to Sing et al. [3] the ash produced by controlled burning of agro waste materials below $700^{\circ} \mathrm{C}$ transforms silica content of the ash into amorphous $\mathrm{SiO}_{2}$ and can be used as pozzolanic material.

Recently, the use of agriculture solid waste materials as pozzolans in the manufacture of blended mortars and concrete has been focused in research [4-6]. ASTM C618 [7] classified SCBA as N pozzolan and adapted for use in making cement $[8,9]$. SCBA has proved to be a viable byproduct for admixture in cement, with its intrinsic characteristic such as high content of silica in the form of quartz [2]. However, the high carbon content is an obstacle for its use in cement/mortars. Therefore it would be valuable if the unburned carbon in SCBA could be removed and used for other applications. In the present study, the collected SCBA and SCWA samples were fired at different temperatures and the calcined SCBA and SCWA were characterized in order to use in different industries.

\section{Experimental}

\subsection{Materials and methods}

SCBA and SCW were collected from Joypurhat Sugar Mill, Joypurhat, Bangladesh. Sugarcane waste was dried, crushed and then sieved by passing 250 microns (Fritsch Analysette 3). Both SCBA and SCW samples have been calcined at $400^{\circ} \mathrm{C}, 600^{\circ} \mathrm{C}, 800^{\circ} \mathrm{C}$ and $1000^{\circ} \mathrm{C}$ for $2 \mathrm{~h}$ under controlled condition. At the end of each process, the ash was taken out of the furnace and cooled at room temperature. After cooling, the ash was stored for characterization. Under this condition the grey and grey white color of the SCBA and sugarcane waste ash (SCWA) indicate complete burning (Fig. 1) of samples.

The oxides were determined by X-ray fluorescence (XRF) spectrometer method following the standard procedure as described by Rigaku Corporation using Rigaku ZSX Primus XRF machine equipped with an end window $4 \mathrm{~kW}$ Rh-anode X-ray tube. The phase identification of the uncalcined and calcined samples were determined by X-ray diffraction (XRD) method with Bruker XRD operating with a CuKa radiation source $(\mathrm{K} \alpha=1.5406 \AA)$.

The percentage of carbon was measured by an Elemental Analyzer (EA 1108). A laser diffraction particle size analyzer (MICROTRAC S-3500) was used to measure particle size distribution. The loss of ignition was determined by the mass loss of these samples after heating at $1000^{\circ} \mathrm{C}$. 

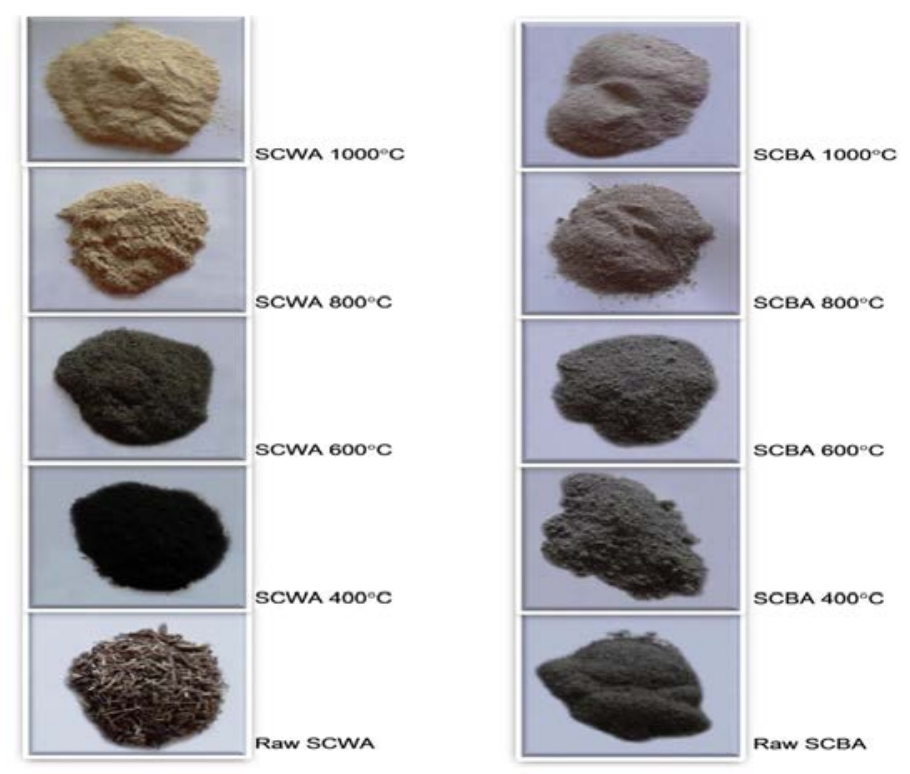

Fig. 1. Uncalcined and calcined sugarcane waste ash (SCWA) and bagasse ash (SCBA) at temperatures $400^{\circ} \mathrm{C}, 600^{\circ} \mathrm{C}, 800^{\circ} \mathrm{C}$ and $1000^{\circ} \mathrm{C}$.

\section{Results and Discussions}

\subsection{Chemical analysis}

The chemical compositions of the bagasse ash and sugarcane waste are given in Tables 1 and 2 respectively. It can be seen that the bagasse ash waste powder contains a significant amount of silica and this amount increase with increasing temperature.

Table 1. Chemical compositions of uncalcined and calcined bagasse ash (SCBA).

\begin{tabular}{lccccc}
\hline \multicolumn{1}{c}{ Oxides (\%) } & Raw SCBA & $400^{\circ} \mathrm{C}$ & $600^{\circ} \mathrm{C}$ & $800^{\circ} \mathrm{C}$ & $1000^{\circ} \mathrm{C}$ \\
\hline $\mathrm{SiO}_{2}$ & 60.75 & 62.55 & 61.93 & 62.57 & 62.40 \\
$\mathrm{Al}_{2} \mathrm{O}_{3}$ & 4.14 & 4.31 & 4.44 & 4.70 & 5.02 \\
$\mathrm{Na}_{2} \mathrm{O}$ & 0.77 & 0.66 & 0.74 & 0.86 & 0.83 \\
$\mathrm{MgO}$ & 2.39 & 2.20 & 2.43 & 2.34 & 2.27 \\
$\mathrm{P}_{2} \mathrm{O}_{5}$ & 3.39 & 3.37 & 3.42 & 3.40 & 3.46 \\
$\mathrm{SO}_{3}$ & 1.81 & 1.70 & 1.73 & 1.71 & 1.79 \\
$\mathrm{~K}_{2} \mathrm{O}$ & 14.63 & 14.37 & 14.25 & 13.86 & 13.40 \\
$\mathrm{CaO}$ & 4.48 & 3.56 & 3.71 & 3.49 & 3.69 \\
$\mathrm{Fe}_{2} \mathrm{O}_{3}$ & 5.27 & 4.88 & 5.01 & 4.87 & 5.71 \\
\hline
\end{tabular}

Table 3 shows the chemical compositions of calcined SCBA and SCWA compared to the composition of coal fly ashes, classified by ASTM [7] by their aggregate alumina, silica and ferric oxide content into class F or C. Generally Class F type coal ashes are 
produced by higher rank coals and have lower calcium content whereas class $\mathrm{C}$ type ashes have higher than $20 \%$ calcium oxide.

The chemical compositions of SCBA confirmed to be a good pozzolana since the sum of alumina, silica and ferric oxide is $70.10 \%$ for raw material and $73.13 \%$ when sample calcined at $1000^{\circ} \mathrm{C}$, thus meeting the requirement of $70 \%$ minimum recommended by ASTM C618 [7].

Table 2. Chemical compositions of uncalcined and calcined sugarcane waste (SCWA).

\begin{tabular}{cccccc}
\hline Oxides $(\%)$ & Raw SCWA & $400^{\circ} \mathrm{C}$ & $600^{\circ} \mathrm{C}$ & $800^{\circ} \mathrm{C}$ & $1000^{\circ} \mathrm{C}$ \\
\hline $\mathrm{SiO}_{2}$ & 15.61 & 18.62 & 20.39 & 20.59 & 23.20 \\
$\mathrm{Al}_{2} \mathrm{O}_{3}$ & 3.22 & 4.06 & 4.75 & 4.99 & 5.28 \\
$\mathrm{Na}_{2} \mathrm{O}$ & 0.10 & 0.27 & 0.25 & 0.37 & 0.52 \\
$\mathrm{MgO}$ & 1.38 & 1.97 & 2.02 & 2.07 & 2.10 \\
$\mathrm{P}_{2} \mathrm{O}_{5}$ & 10.82 & 12.87 & 14.16 & 14.07 & 14.63 \\
$\mathrm{SO}_{3}$ & 11.95 & 8.72 & 8.38 & 8.93 & 6.71 \\
$\mathrm{~K}_{2} \mathrm{O}$ & 6.48 & 5.45 & 5.42 & 5.06 & 4.52 \\
$\mathrm{CaO}$ & 40.24 & 40.22 & 38.64 & 37.48 & 36.78 \\
$\mathrm{Fe}_{2} \mathrm{O}_{3}$ & 7.32 & 5.52 & 3.98 & 4.34 & 4.39 \\
\hline
\end{tabular}

Table 3. Comparison between chemical compositions of calcined $\left(800^{\circ}\right.$ and $\left.1000^{\circ} \mathrm{C}\right)$ SCBA and SCWA $\left(800^{\circ}\right.$ and $\left.1000^{\circ} \mathrm{C}\right)$ and pulverized coal fly ashes ASTM C 618 Classification.

\begin{tabular}{ccccccc}
\hline $\begin{array}{c}\text { Oxide } \\
(\%)\end{array}$ & $\begin{array}{c}\text { SCBA } \\
800^{\circ} \mathrm{C}\end{array}$ & $\begin{array}{c}\text { SCBA } \\
1000^{\circ} \mathrm{C}\end{array}$ & $\begin{array}{c}\text { SCWA } \\
800^{\circ} \mathrm{C}\end{array}$ & $\begin{array}{c}\text { SCWA } \\
1000^{\circ} \mathrm{C}\end{array}$ & $\begin{array}{c}\text { Class F } \\
\text { fly ash }\end{array}$ & $\begin{array}{c}\text { Class C fly } \\
\text { ash }\end{array}$ \\
\hline $\mathrm{SiO}_{2}$ & 62.57 & 62.40 & 20.59 & 23.20 & $40-63$ & $32-42$ \\
$\mathrm{Al}_{2} \mathrm{O}_{3}$ & 4.70 & 5.02 & 4.99 & 5.28 & $17-28$ & $15-20$ \\
$\mathrm{Fe}_{2} \mathrm{O}_{3}$ & 4.87 & 4.39 & 4.34 & 4.39 & $3-12$ & $5-7$ \\
$\mathrm{MgO}$ & 2.34 & 2.27 & 2.07 & 2.10 & $0.6-2$ & $4.1-6.1$ \\
$\mathrm{CaO}$ & 3.49 & 3.69 & 37.48 & 36.78 & $2-8$ & $15-35$ \\
Loss of & 1.27 & 0.37 & 2.06 & 0.77 & $0-5$ & $0-0.5$ \\
Ignition & & & & & & \\
\hline
\end{tabular}

From Table 3, the chemical compositions of the calcined SCBA is seen to resemble that of Class F coal fly ash especially in terms of the total of alumina, silica and ferric oxide content. Therefore, it may behave like class F Fly ash in its properties. On the other hand calcined SCWA is seen to resemble that of Class C coal fly ash especially in terms of the total of alumina, ferric and calcium oxide content.

Fig. 2 shows the percentage of carbon content of SCBA and SCWA. The percentage of carbon indicates that raw bagasse ash decreases $63 \%$ when sample is calcined at $400^{\circ} \mathrm{C}$ and $97 \%$ decrease when calcined at $1000^{\circ} \mathrm{C}$. Carbon percentage of sugarcane waste also significantly reduced when sample was calcined at different temperatures. These results indicate that carbon percentage is significantly decreased at $800^{\circ} \mathrm{C}$ and $1000^{\circ} \mathrm{C}$ for SCWA. The carbon and volatile compounds present in the SCBA are expected to be considerably removed at higher calcinations temperature [10]. 

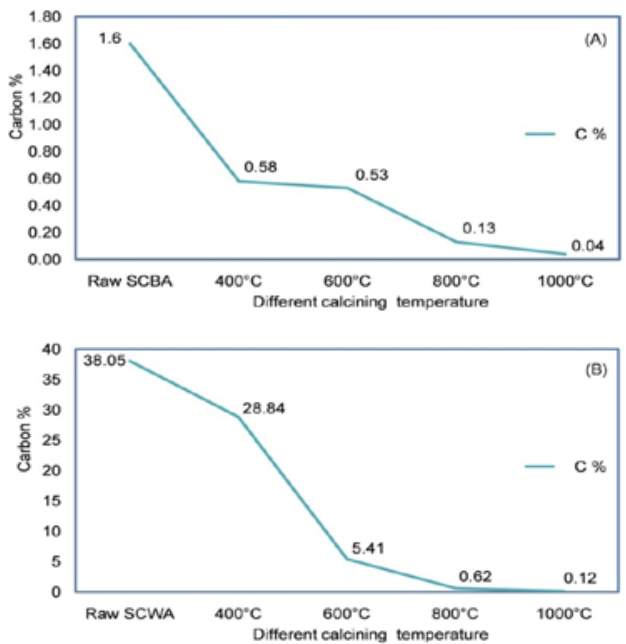

Fig. 2. Percentage of carbon of uncalcined and calcined SCBA (A) and SCWA (B).

\subsection{Particle size analysis}

Fig. 3(A)-(B) show particle size distribution of SCBA and SCWA respectively. Particle size distributions are almost similar at different calcined temperature for SCBA (Fig. 3A), however, particle size distribution curve provided slightly bimodal distribution at $600^{\circ} \mathrm{C}$. For SCWA (Fig. 3B), particle size distribution shifted from $400^{\circ} \mathrm{C}$ towards left side at higher temperature due to reduction of particle size.
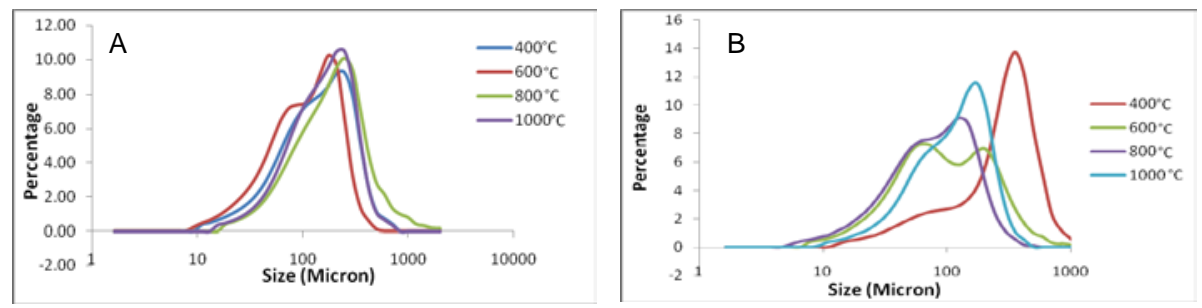

Fig. 3. Particle size distribution of SCBA (A) and SCWA (B) in dependence of calcination temperature.

\subsection{Phase analysis at different calcination temperatures}

The burning of organic materials containing higher amounts of silica in their cuticle parts produced crystallization of amorphous silica which gradually converted to different phases of silica with the increase in temperature [11]. The XRD patterns showed a remarkable difference between calcined and raw SCBA, which suggests that phase 
transformation occurred (Fig. 4A) with the increase of calcining temperature. For SCBA, silica (quartz) is the primary component with small amounts of calcium compound the temperature of $400^{\circ}$ and $600^{\circ} \mathrm{C}$. At $800^{\circ} \mathrm{C}$, some sharp and intense peaks started (quartz and sillimanite) to show up, which implies that the crystallanity increases as temperature rises. Ribeiro and Morell [12] also reported similar observation on SCBA.

In raw SCW (Fig. 4B), silica and carbon are the primary components with other calcium compounds (calcite and feldspar). In the case of SCWA at $800^{\circ}$ and $1000^{\circ} \mathrm{C}$, some sharp peaks of silica (quartz and cristobalite) started to show up and more $\mathrm{SiO}_{2}$ phases are observed. According to Faria et al. [6] calcinations of sugarcane straw ash at $1000^{\circ} \mathrm{C}$ increased the crystallinity and cristobalite is the main crystalline form detected at this calcining temperature.
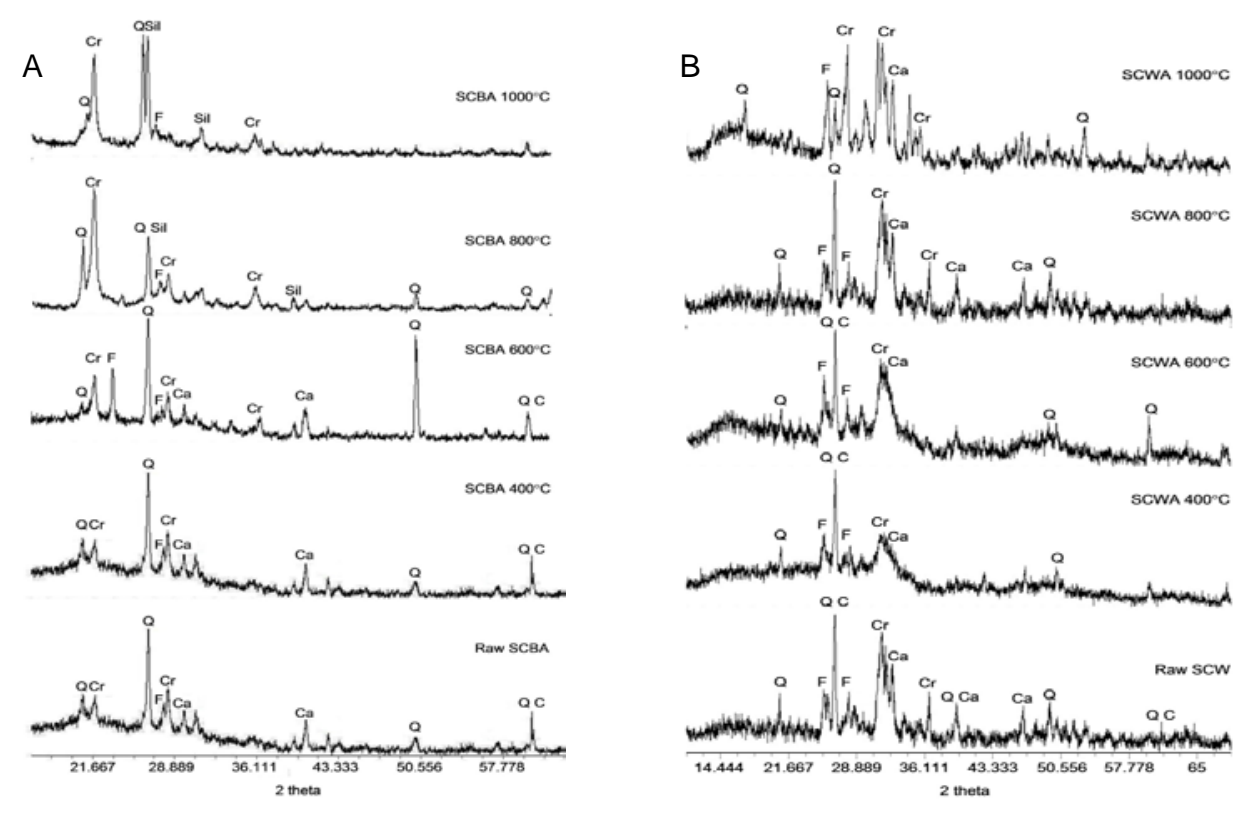

Fig. 4. XRD patterns of uncalcined and calcined SCBA (A) and SCWA (B) at different temperatures (Q-Quartz, Cr-Cristobalite, Sil-Sillimanite, F-Feldspar, Ca-Calcium, C-Carbon).

\section{Conclusion}

From the analysis of the results given above, the followings conclusions can be made:

1) SCBA and SCWA can be recycled as additives or raw material when calcined in the range of $600-1000^{\circ} \mathrm{C}$.

2) As temperature increases, the color of SCBA and SCWA changes from black to grey and white, indicates that the carbon content present in the samples were reasonably reduced. 
3) Carbon percentages obtained from elemental analyzer also confirmed minimization of carbon content with increase of calcining temperature.

4) The chemical composition of calcined SCBA and SCWA indicated that it has more or less the same composition of other pozzolanic materials like fly ash, that these materials may be used for low cost building material such as blocks and bricks. These may be successfully used as an engineering material for a wide variety of applications.

5) XRD patterns showed that crystallinity increases with the increase of calcining temperature for both SCBA and SCWA calcined samples.

\section{Acknowledgement}

The authors would like to thank Institute of Fuel Research and Development (IFRD), BCSIR, Dhaka for the carbon percent analysis by elemental analyzer and PP \& PDC, BCSIR, Dhaka, Bangladesh for support with XRD analysis.

\section{References}

1. K. Ganesan, K. Rajagopal, and K. Thangavel, Cement Concrete Composites 29, 515 (2007). http://dx.doi.org/10.1016/j.cemconcomp.2007.03.001

2. D. Govindarajan and G. Jayalakshmi, Adv. Appl. Sci. Res. 2(3), 544 (2011).

3. N. B. Singh, S. S. Das, N. P. Singh, and V. N. Dwivedi, Ind. J. Eng. Mater. Sci. 16, 415 (2000).

4. J. Payá, J. Monzó, M. V. Borrachero, L. Díaz-Pinzón, and L. M. Ordóñez, J. Chem. Tech. Biotech. 77(3), 321 (2002). http://dx.doi.org/10.1002/jctb.549

5. A. Goyal, H. Kunio, Ogata, and Mandula, in Properties and Reactivity of Sugarcane Bagasse Ash - Proc. 12th Int. Colloquim on Struct. \& Geotechnical Eng. (Cairo, Egypt, 2007) 1, pp. 15.

6. K. C. P. Faria, R. F. Gurgel, and J. N. F. Holanda, J. Environ. Manag. 101, 7 (2012). http://dx.doi.org/10.1016/j.jenvman.2012.01.032

7. American Society for Testing and Materials Standards ASTM C618, Standard Specification for Fly Ash and Raw or Calcium Natural Pozzolanas for Use as a Mineral Admixture in Portland Cement Concrete, (Pennsylvania, USA, 1992) 04.02.

8. A. R. Mead, in Temperature-Instrumentation Observations at Pine Flat and Folsom Dams Symp. on Mass Concrete, SP-6 (American Concrete Institute, Detroit, 1963) pp. 151-178.

9. R. G. Smith, British Build. Soc. J. 1 (1992)

10. G. C. Cordeiro, R. D. T. Filho, and E. M. R. Fairbairn, Constr. Build. Mater. 23, 113 (2009). http://dx.doi.org/10.1016/j.conbuildmat.2009.02.013

11. N. M. Altwair, M. A. M. Johari, and S. F. S. Hashim, Aus. J. Basic Appl. Sci. 5(11), 1010 (2011).

12. D. V. Ribeiro and M. R. Morelli, Mat. Res. 17(4), (2014). http://dx.doi.org/10.1590/S1516$\underline{14392014005000093}$ 